\title{
Balanço energético da produção de grãos, carne e biocombustíveis em sistemas especializados e mistos
}

\author{
Jerusa Maia e Sá(1), Segundo Urquiaga(2), Cláudia Pozzi Jantalia(2), Luis Henrique de Barros Soares(2), \\ Bruno José Rodrigues Alves ${ }^{(2)}$, Robert Michael Boddey ${ }^{(2)}$, Robélio Leandro Marchão(3) e Lourival Vilela(3) \\ (1)Universidade Federal Rural do Rio de Janeiro, Departamento de Fitotecnia, BR-465, Km 7, CEP 23890-000 Seropédica, \\ RJ. E-mail: jerusamaiasa@yahoo.com.br (2)Embrapa Agrobiologia, BR-465, Km 7, CEP 23890-000 Seropédica, RJ. E-mail: \\ segundo.urquiaga@embrapa.br, claudia.jantalia@embrapa.br,luis.soares@embrapa.br,bruno.alves@embrapa.br,robert.boddey@embrapa.br \\ (3)Embrapa Cerrados, BR 020, Km 18, CEP 73310-970 Planaltina, DF. E-mail: robelio.marchao@embrapa.br, lourival.vilela@embrapa.br
}

Resumo - O objetivo deste trabalho foi avaliar a eficiência energética de sistemas especializados e mistos de produção de grãos e carne e o balanço energético na produção de bioenergia. Foram avaliados dados de 20 anos de cultivo com sistemas agrícolas especializados e mistos. Como sistemas agrícolas especializados, avaliaramse: a pastagem de gramínea; a pastagem de gramínea consorciada com leguminosa; e a produção de grãos em sistema plantio direto ou em sistema convencional de preparo do solo. Como sistema misto, considerou-se a integração lavoura-pecuária em dois sistemas de manejo. Os insumos utilizados foram considerados como o ingresso energético, enquanto a produção de grãos e carne, as saídas de energia. Os produtos agrícolas nos sistemas mistos apresentaram balanço energético e produção absoluta de energia renovável compatíveis com aqueles produzidos em sistemas especializados. O balanço energético do biocombustível de soja apresentou valores positivos tanto em sistemas mistos como especializados, independentemente do sistema de preparo do solo. Entre os biocombustíveis de soja e milho analisados, o maior balanço energético foi observado no bioetanol produzido com milho. Os biocombustíveis produzidos em todos os sistemas apresentam balanço energético positivo e podem ser considerados energeticamente sustentáveis.

Termos para indexação: bioenergia, eficiência energética, integração lavoura-pecuária, pastagem, produção sustentável de alimentos.

\section{Energy balance for the production of grain, meat, and biofuel in specialized and mixed agrosystems}

\begin{abstract}
The objective of this work was to evaluate the energetic efficiency of mixed and specialized production systems of grain and meat, and the energy balance in bioenergy production. Agronomic data from 20 -year farming with specialized and mixed agrosystems were used. As specialized agricultural systems, the following ones were evaluated: grass pasture; grass with legume pasture; and continuous grain production under no tillage or conventional plough tillage. As a mixed system, the integrated crop-livestock was evaluated under no tillage or conventional plough tillage. The agricultural activity were considered energy input, while grain yield and meat production the energy output. The agricultural products obtained in mixed systems showed energy balance and total production of renewable energy equivalent to the those yielded by the specialized systems. The energy balance of soybean biofuel showed positive values both in mixed and in specialized systems regardless of the soil tillage managements. Among the analyzed soybean and maize biofuels, the greatest energy balance was observed in maize bioethanol. The biofuels produced in all production systems show a positive energy balance and can be considered energetically sustainable.
\end{abstract}

Index terms: bioenergy, energy efficiency, crop-livestock integration, pasture, sustainable food production.

\section{Introdução}

O Cerrado constitui o maior celeiro agrícola brasileiro apto ao desenvolvimento de programas de exploração de culturas agroenergéticas. Fontes energéticas renováveis alternativas podem substituir significativas quantidades de energia proveniente de fontes não renováveis. Entretanto, premissas como a viabilidade econômica, oferta de recursos renováveis e a sustentabilidade destas alternativas devem ser avaliadas (Soares et al., 2007). Para que não se invalidem os efeitos positivos ambientais e econômicos dos produtos que substituem fontes de energia fósseis por renováveis, o Plano Nacional de Agroenergia 
propôs a elaboração dos balanços de energia em toda a cadeia produtiva (Plano Nacional de Agroenergia 2006-2011, 2006).

O balanço energético é um dos indicadores mais adequados para ajuizar a viabilidade técnica de qualquer programa bioenergético (Urquiaga et al., 2005). Além disto, indica condições de manejo mais adequadas e permite a identificação dos gargalos do sistema passíveis de melhoria para o aumento da eficiência (Mello, 1989; Assenheimer et al., 2009). $\mathrm{O}$ balanço energético deve ser determinado por medidas diretas dos parâmetros do sistema e, para seu cálculo, é feito o levantamento dos insumos utilizados, e os valores são convertidos em energia, para se estabelecer uma relação de eficiência do sistema de produção. Este processo é o elemento-chave para as tomadas de decisões relativas à redução dos custos de produção com uso energético intensivo, por meio da economia de energia e do aumento da eficiência no uso dos insumos (Campos \& Campos, 2004).

Há grande interesse na determinação do impacto das diferentes atividades econômicas, seja pela análise do ciclo de vida, pegada de carbono ou eficiência energética dos produtos (Cherubini \& Strømman, 2011; Cucek et al., 2012). Assim, mesmo quando o foco não é a eficiência energética, é possível transformar estas informações em termos de componentes energéticos, para diagnosticar a eficácia da produção e a conversão de energia nos sistemas agrícolas (Campos \& Campos, 2004). Estes resultados podem contribuir para práticas de manejo agropecuárias mais eficientes e para o aumento da eficiência energética geral.

Os processos que conciliam geração de produtos sem afetar significativamente o ambiente, tendem a ser menos dispendiosos, em razão da menor manipulação do ecossistema em qual estão inseridos (Pimentel \& Hall, 1984). A integração lavoura-pecuária reúne diferentes técnicas produtivas que são adequadas para que a produção de grãos e carne seja compensatória (Vilela et al., 2011). A adoção deste sistema, em diferentes regiões brasileiras, está sendo estimulada principalmente entre os produtores especializados em grãos ou carne. Dentro da perspectiva de que a produção futura de grãos e carne seja feita em sistemas mistos de produção, há grande interesse em se avaliar sua eficiência energética em relação aos sistemas especializados (Marta Júnior, 2008).
O objetivo deste trabalho foi avaliar o balanço energético da produção de grãos, carne e biocombustíveis, obtidos em sistemas agrícolas mistos e especializados após 20 anos de cultivo.

\section{Material e Métodos}

Neste estudo, foram consideradas as atividades fitotécnicas e as produções médias de grãos e carne, obtidas em um experimento de longo prazo com sistemas especializados e mistos da Embrapa Cerrados, em Planaltina, DF, a $15^{\circ} 35^{\prime} 30^{\prime \prime} \mathrm{S}, 47^{\circ} 42^{\prime} 00^{\prime \prime} \mathrm{W}$, a $1.175 \mathrm{~m}$ de altitude. Os dados foram obtidos por meio de entrevistas com técnicos e pesquisadores envolvidos desde a implantação do experimento, assim como consulta a trabalhos e relatórios técnicos referentes a este.

O período avaliado compreendeu a implantação do experimento em 1991 até o ano de 2010, no total de 20 anos. A partir destes dados, realizou-se um inventário com todo o histórico de utilização de insumos e da produção média. Para uma análise descritiva da eficiência energética e do balanço energético de diferentes sistemas agrícolas especializados e mistos, realizou-se a conversão em energia de todos os componentes de produção. Os cálculos de entradas e saídas energéticas tiveram como base um hectare. Os tratamentos foram agrupados de acordo com a semelhança do produto gerado, para se avaliar a eficiência entre os sistemas.

Para a produção de biocombustíveis, na análise do balanço energético de grãos, considerou-se que a produção média da soja fosse destinada à produção de biodiesel, pelo processo de transesterificação industrial, e o milho para produção de bioetanol, por meio da hidrólise e sacarificação do amido, seguida da fermentação industrial. $\mathrm{Na}$ produção dos biocombustíveis, utilizou-se o consumo médio referente ao processamento industrial, conforme Boddey et al. (2008). Por definição, o balanço energético é adimensional, por estabelecer apenas uma relação entre entradas e saídas energéticas (Pimentel \& Hall, 1984). Considerou-se que os biocombustíveis teriam o balanço energético expressos em relação a 1 (um) unidade de energia gasta para um determinado valor de saída - calculados por meio do inventário realizado. Assim, para a obtenção do balanço energético, utilizou-se a razão entre a energia produzida pelo 
sistema (saída), com a energia investida para obtenção dos produtos agrícolas (entrada), conforme Melo et al. (2007), Macedo et al. (2008) e Campos et al. (2009).

Foram avaliados os seguintes sistemas especializados de produção agrícola: pastagem contínua, em monocultivo de gramínea (S1); pastagem contínua de gramínea, consorciada com leguminosa (S2); e lavoura contínua (S4), em sistema de preparo do solo plantio direto (PD) e preparo convencional (PC). Os sistemas mistos avaliados foram: integração lavoura-pecuária (ILP), que se iniciou com rotação pasto/lavoura (S3P) em sistema plantio direto e preparo convencional; e ILP, que iniciou com rotação lavoura/pasto (S3L), também em sistema plantio direto e preparo convencional.

No presente estudo, considerou-se apenas o gasto energético no preparo e manutenção da área experimental, assim como a média dos produtos gerados (carne ou grãos ou ambos) em cada tratamento. $\mathrm{Na}$ determinação do balanço energético, considerouse como saída a energia calorimétrica total dos grãos (Rostagno et al., 2005) e o conteúdo calórico do ganho de peso animal (Sant'ana et al., 2011).

Durante o preparo e manejo da área, em 1990, a vegetaçãode cerrado nativo foi substituída por diferentes sistemas de manejo e uso do solo. No desmatamento da vegetação de cerrado, utilizaram-se dois tratores interligados com cabo de aço para o tombamento da vegetação, rastelagem e pulverização de herbicida, com um consumo de $60 \mathrm{~L} \mathrm{ha}^{-1}$ de óleo diesel. Para a instalação e manutenção da área de cada tratamento, adotou-se o mesmo critério utilizado por Boddey et al. (2008), que consideraram a mesma demanda de mão de obra (122 horas por ano) em todos os sistemas agrícolas, com o consumo energético de 7,84 MJ por hora por homem. No estabelecimento do experimento, em 1991, aplicou-se calcário dolomítico à dose de $5,8 \mathrm{Mg} \mathrm{ha}^{-1}$. A área foi, então, dividida em blocos, para a casualização dos diferentes sistemas agrícolas, com quatro repetições. O preparo convencional do solo (PC) consistiu de uma aração e duas gradagens; e, no sistema plantio direto (PD), utilizou-se a aplicação de herbicida à dose média de $2 \mathrm{~L} \mathrm{ha}^{-1}$ de glifosato.

A manutenção das pastagens contínuas foi realizada com adubação de correção, tendo-se levado em conta a saturação de bases a $50 \%+20 \mathrm{~kg}$ de $\mathrm{P}_{2} \mathrm{O}_{5}+50 \mathrm{~kg}$ de $\mathrm{K}_{2} \mathrm{O}+60 \mathrm{~kg}$ de $\mathrm{N} \mathrm{ha}^{-1}$ por ano. Nas pastagens contínuas, realizaram-se mais duas aplicações de calcário, no total de $7,9 \mathrm{Mg} \mathrm{ha}^{-1}$. Nos tratamentos da ILP, não houve fertilização do solo para o cultivo da pastagem. Nas áreas exploradas com culturas de grãos, procedeuse à adubação corretiva gradual. No tratamento S2, não se aplicou o fertilizante mineral nitrogenado. $\mathrm{O}$ gasto energético com os macronutrientes e calcário aplicado levou em consideração apenas o consumo energético na fabricação do adubo mineral e calcário, sem se considerar o custo com o transporte.

Nas áreas com pastagem, utilizou-se o sistema de pastejo rotacionado, com animais da raça Nelore, em períodos de ocupação e descanso de 14 dias durante a estação chuvosa (180 dias). A oferta de forragem (8 a $10 \mathrm{~kg}$ de matéria verde por $100 \mathrm{~kg}$ de peso vivo) foi constante e ajustada a cada 28 dias. Na ILP, a rotação pasto-lavoura (S3P) e lavoura-pasto (S3L) foi realizada a cada 4 anos. Na Tabela 1, encontra-se a sequência das culturas de grãos e forrageiras utilizadas em cada tratamento.

As sementes de soja receberam inoculação de Bradyrhizobium sp., com 80 g de inoculante comercial para $50 \mathrm{~kg}$ de sementes. O dispêndio energético da fabricação dos pesticidas agrícolas levou em consideração a média de índices energéticos conhecidos para os princípios ativos de cada classe de insumo: inseticida, fungicida e herbicida (Pimentel, 1980).

Para a determinação do conteúdo energético do ganho de peso animal, calculou-se o valor energético por quilograma, por meio de uma equação alométrica (Sant'ana et al., 2011). O peso médio dos animais utilizados no cálculo da eficiência energética foi a diferença do peso de entrada e saída dos animais nas pastagens. O peso inicial foi de 178, 184, 190 e $189 \mathrm{~kg}$, e o peso final foi de $326,298,327$ e $326 \mathrm{~kg}$ para os sistemas S1, S2, S3PC e S3PD, respectivamente. Para a prevenção de doenças endêmicas, os animais foram vacinados contra febre aftosa, raiva bovina e brucelose e, para o controle de ectoparasitas, foi aplicado o banho nos animais, com cipermetrina a $6 \%$. O sal mineral foi utilizado como meio de suplementação alimentar, dose de consumo aproximada de $30 \mathrm{~g}$ por animal por dia.

As entradas energéticas na forma de arames, moirões e depreciação de implementos não foram contabilizados. Determinou-se que o investimento energético da fabricação das máquinas agrícolas foi compensado durante todo o tempo de trabalho, 15 anos de uso, além de sua utilização nas demais áreas experimentais, o que poderia subestimar a eficiência energética dos sistemas avaliados.

Pesq. agropec. bras., Brasília, v.48, n.10, p.1323-1331, out. 2013 DOI: 10.1590/S0100-204X2013001000003 
O consumo de óleo diesel dos tratores consistiu das informações do rendimento e do consumo de diesel do trator utilizado na área de estudo, para as operações de aração, gradagem e demais operações, como aplicação de calcário, fertilizantes e outros insumos. Para insumos muito específicos e de contribuição pouco expressiva, estimou-se o valor energético com base no custo de uma unidade monetária para o Produto Interno Bruto relacionado ao Balanço Energético Nacional, ambos de 2010 (Mello, 1989; Soares et al., 2007).

\section{Resultados e Discussão}

O desempenho energético nos sistemas especializados com pastagens foi favorável (Tabela 2). Nas pastagens avaliadas, o retorno em energia foi cem vezes superior à energia investida ao longo do período avaliado. Apesar de não haver diferença acentuada de produtividade animal, entre os sistemas S1 e S2, o balanço energético na pastagem consorciada foi superior ao do monocultivo de gramínea, em decorrência do menor consumo associado ao investimento energético em fertilizantes e corretivos. Este valor representou $27,71 \%$ na pastagem em monocultivo de gramínea e
$12,68 \%$ na pastagem consorciada. $\mathrm{O}$ uso da leguminosa em consórcio representou a economia de $6,36 \mathrm{GJ}$, por não se utilizar a adubação nitrogenada, pois, os demais nutrientes foram aplicados na mesma quantidade. Resultado semelhante foi obtido por Campos et al. (2004), que observaram consumo energético correspondente a 10,61 GJ, perfazendo $17,43 \%$ da produção de alfafa para fenação, em Coronel Pacheco, MG.

O consumo de combustível representou 19,28 e $27,03 \%$ nos sistemas monocultivo e leguminosas, respectivamente. Esta diferença está associada à maior utilização de mecanização agrícola, nas práticas de reforma de pastagem de gramínea consorciada com leguminosa, quando da substituição da leguminosa forrageira.

Nos sistemas de produção contínuos de grãos, os valores de eficiência do balanço energético são notadamente menores do que aqueles observados nas pastagens (Tabela 3). Na produção contínua de grãos, os resultados observados no balanço energético em plantio direto foram mais eficientes do que os de plantio convencional. Esta diferença está associada às distintas produtividades de grãos, consumo de herbicida e combustível. A percentagem de consumo

Tabela 1. Culturas utilizadas em diferentes sistemas de manejo, avaliados no período de 1991 a 2010, em experimento da Embrapa Cerrados, Planaltina, DF.

\begin{tabular}{|c|c|c|c|c|c|}
\hline \multirow{2}{*}{ Ano } & \multicolumn{2}{|r|}{ Pastagem contínua $^{(1)}$} & \multicolumn{2}{|c|}{ Integração lavoura-pecuária (S3) } & \multirow{2}{*}{$\begin{array}{l}\text { Lavoura contínua } \\
\text { (S4) }\end{array}$} \\
\hline & Gramínea (S1) & Consorciada com leguminosa (S2) & Rotação pasto/lavoura & Rotação lavoura/pasto & \\
\hline 1991 & Ag. 'Planaltina' & Ag. 'Planaltina' + Sg. 'Mineirão' & Ag. 'Planaltina' & Soja 'Doko' & Soja 'Doko' \\
\hline 1992 & Ag. 'Planaltina' & Ag. 'Planaltina' + Sg. 'Mineirão' & Ag. 'Planaltina' & Soja 'Sirirema' & Soja 'Sirirema' \\
\hline 1993 & Ag. 'Planaltina' & Ag. 'Planaltina' + Sg. 'Mineirão' & Ag. 'Planaltina' & Milho BR 2001 & Milho BR 2001 \\
\hline 1994 & Ag. 'Planaltina' & Ag. 'Planaltina' + Sg. 'Mineirão' & Ag. 'Planaltina' & Soja 'Savana' & Soja 'Savana' \\
\hline 1995 & Ag. 'Planaltina' & Ag. 'Planaltina' + Sg. 'Mineirão' & Milho BR 205 & Ag. 'Planaltina' & Milho BR 205 \\
\hline 1996 & Ag. 'Planaltina' & Ag. 'Planaltina' + Sg. 'Mineirão' & Soja 'Savana' & Ag. 'Planaltina' & Soja 'Savana' \\
\hline 1997 & Ag. 'Planaltina' & Ag. 'Planaltina' + Sg. 'Mineirão' & Milho BR 205 & Ag. 'Planaltina' & Milho BR 205 \\
\hline 1998 & Ag. 'Planaltina' & Ag. 'Planaltina' + Sg. 'Mineirão' & Soja 'Celeste' & Ag. 'Planaltina' & Soja 'Celeste' \\
\hline 1999 & Ag. 'Planaltina' & Ag. 'Planaltina' + Sg. cv. 'Mineirão' & Panicum maximum 'Tanzânia' & Soja 'Milena' & Soja 'Milena' \\
\hline 2000 & B. decumbens & Bd. + Sg. 'Mineirão' & Panicum maximum 'Tanzânia' & Milheto 'CPAC' & Milheto 'CPAC' \\
\hline 2001 & B. decumbens & Bd. + Sg. 'Mineirão' & Panicum maximum 'Tanzânia' & Soja 'Nina' & Soja 'Nina' \\
\hline 2002 & B. decumbens & Bd. + Sg. 'Mineirão' & Panicum maximum 'Tanzânia' & Milheto 'CPAC' & Milheto 'CPAC' \\
\hline 2003 & B. decumbens & Bd. + Sg. 'Mineirão' & Panicum maximum 'Tanzânia' & $\begin{array}{l}\text { Soja 'Raimunda' + Bd. } \\
\text { 'Marandu' }\end{array}$ & Soja 'Raimunda' \\
\hline 2004 & B. decumbens & Bd. + Sg. 'Mineirão' & Soja 'Emgopa 313' & Bd. 'Marandu' & Soja 'Emgopa 313' \\
\hline 2005 & B. decumbens & Bd. + Sg. 'Mineirão' & Sorgo BR 304 & Bd. 'Marandu' & Sorgo BR 304 \\
\hline 2006 & B. decumbens & Bd. + Cajanus cajan & Soja 'Valiosa' & Bd. 'Marandu' & Soja 'Valiosa' \\
\hline 2007 & B. decumbens & Bd. + Cajanus cajan & $\begin{array}{l}\text { Brachiaria brizantha 'Piatã' + } \\
\text { Milheto 'CPAC' }\end{array}$ & Soja 'Valiosa rr' & Soja 'Valiosa rr' \\
\hline 2008 & B. decumbens & Bd. + Cajanus cajan & Bd. 'Piatã' & Milho BRS 1010 & Milho BRS 1010 \\
\hline 2009 & B. decumbens & Bd. + Cajanus cajan & Bd. 'Piatã' & Soja 'Valiosa rr' & Soja 'Valiosa rr' \\
\hline 2010 & B. decumbens & Bd. + Cajanus cajan & Bd. 'Piatã' & Soja 'Valiosa rr & Soja 'Valiosa rr' \\
\hline
\end{tabular}

(1)Ag., Andropogon gayanus; Sg., Stylosanthes guianensis; Bd., Brachiaria decumbens; rr, roundup ready. 
de herbicida representou $12,83 \%$ do total de energia investida no plantio direto (S4PD), enquanto no plantio convencional (S4PC), foi de $2,71 \%$. Em relação ao total de investimento energético, os gastos energéticos com combustível fóssil corresponderam a 13,50 e $37,85 \%$, respectivamente, em S4PD e S4PC (Tabela 3). O não revolvimento do solo em S4PD permitiu maior economia de energia no sistema produtivo; no entanto, a prática de dessecação das plantas, após a colheita no plantio direto, diminuiu a eficiência energética deste tratamento. Nos sistemas de produção de grãos, houve menor produção de energia renovável por ano, com valores anuais cinco vezes menores do que os observados nos sistemas de produção animal (Tabelas 2 e 3). Esta diferença ocorreu principalmente pela maior aplicação de fertilizantes e pelo consumo de combustíveis, em razão do maior número de operações agrícolas no sistema especializado na produção de grãos.

Em um experimento em Passo Fundo, RS, no período de 1997 a 2003, encontrou-se eficiência energética de $72,44 \mathrm{MJ} \mathrm{ha}^{-1}$, em sistema plantio direto, 64,06 $\mathrm{MJ}^{\text {ha }}{ }^{-1}$ em sistema de cultivo mínimo no inverno e semeadura direta no verão, 54,35 $\mathrm{MJ}^{\text {ha }}{ }^{-1}$ com a utilização de

Tabela 2. Balanço energético da produção animal, em sistemas especializados de pastagem em monocultivo de gramínea e consorciado com leguminosas, durante o período de 1991-2010, em experimento da Embrapa Cerrados, Planaltina, DF.

\begin{tabular}{lcc}
\hline Sistema de manejo & $\begin{array}{c}\text { Pastagem } \\
\text { monocultivo }\end{array}$ & $\begin{array}{c}\text { Pastagem consorciada } \\
\text { com leguminosa }\end{array}$ \\
\hline Produtividade em GPA $\left(\mathrm{Mg} \mathrm{ha}^{-1}\right)$ & 3,39 & 3,75 \\
Ingressos $\left(\mathrm{GJ} \mathrm{ha}^{-1}\right)$ & & \\
Fertilizantes/corretivos & 10,95 & 4,59 \\
Sementes & 0,71 & 1,58 \\
Inseticidas & 0,10 & 0,10 \\
Fungicidas & 0,20 & 0,20 \\
Herbicidas & 0,50 & 0,50 \\
Sanidade animal & 0,14 & 0,14 \\
Sal mineral & 0,14 & 0,14 \\
Combustível & 7,62 & 9,78 \\
Óleo mineral parafínico & 0,02 & 0,02 \\
Mão de obra & 19,13 & 19,13 \\
\hline Total de ingressos (a) & 39,51 & 36,18 \\
\hline Saídas (GJ ha ${ }^{-1}$ ) & & \\
Energia do componente animal (b) & $4.013,72$ & $3.967,65$ \\
Saldo energético médio (b-a)/20 anos & 198,71 & 196,57 \\
\hline Balanço energético (b/a) & 101,59 & 109,66 \\
\hline
\end{tabular}

GPA, ganho de peso animal. arado de discos no inverno e semeadura direta no verão, e 52,02 $\mathrm{MJ} \mathrm{ha}^{-1}$ em preparo do solo com arado de aivecas no inverno e semeadura direta no verão (Santos et al., 2007). Estes mesmos autores constataram que o emprego de rotação de culturas (trigo/soja e ervilhaca/milho ou sorgo; trigo/soja, ervilhaca/milho ou sorgo; e aveia branca/soja) apresentou valores mais elevados de conversão energética que no sistema em monocultivo de inverno e verão (trigo/soja). Em Cuba, o cultivo de milho entre os anos de 2002 a 2004 apresentou economia de 2.326,81 e 1.026,67 $\mathrm{MJ} \mathrm{ha}^{-1}$, nos tratamentos de cultivo mínimo do solo e sistema plantio direto, e estes valores corresponderam a 48,29 e $77,18 \%$, respectivamente, da energia total investida no preparo convencional do solo (Rondón et al., 2005). Por sua vez, Melo et al. (2007) observaram que o consumo com fertilizantes e herbicidas corresponderam a 33,18 e $12,55 \%$, respectivamente, na produção de soja e milho, em sistema plantio direto durante os anos agrícolas de 2001 e 2002 em Medianeira, PR.

Os sistemas mistos de ILP, que se iniciaram em pasto/ lavoura, foram eficientes em termos energéticos, em comparação aos sistemas especializados de produção de grãos e carne. O sistema ILP lavoura/pasto, em plantio direto, resultou em desempenho inferior entre os sistemas mistos (Tabela 4). Os maiores valores observados nos sistemas mistos que se iniciaram com

Tabela 3. Balanço energético em sistemas especializados de produção de grãos sob preparo convencional do solo (S4PC) e plantio direto (S4PD), durante o período de 1991-2010, em experimento da Embrapa Cerrados, Planaltina, DF.

\begin{tabular}{|c|c|c|}
\hline Sistema de manejo & S4PC & S4PD \\
\hline Produtividade grãos $\left(\mathrm{Mg} \mathrm{ha}^{-1}\right)$ & 57,83 & 59,71 \\
\hline \multicolumn{3}{|l|}{ Ingressos $\left(\mathrm{GJ} \mathrm{ha}^{-1}\right)$} \\
\hline Fertilizantes/corretivos & 44,69 & 44,69 \\
\hline Sementes & 29,85 & 29,85 \\
\hline Inoculante & 0,09 & 0,09 \\
\hline Inseticidas & 0,37 & 0,37 \\
\hline Fungicidas & 2,21 & 2,21 \\
\hline Herbicidas & 4,41 & 16,86 \\
\hline Óleo mineral parafínico & 0,22 & 0,39 \\
\hline Combustível & 61,50 & 17,73 \\
\hline Mão de obra & 19,13 & 19,13 \\
\hline Total de ingressos (a) & 162,47 & 131,32 \\
\hline \multicolumn{3}{|l|}{ Rendimento energético $\left(\mathrm{GJ} \mathrm{ha}^{-1}\right)$} \\
\hline Energia da combustão completa dos grãos (b) & 941,69 & 972,20 \\
\hline Saldo energético médio (b-a)/20anos & 38,96 & 42,04 \\
\hline Balanço energético (b/a) & 5,80 & 7,40 \\
\hline
\end{tabular}

Pesq. agropec. bras., Brasília, v.48, n.10, p.1323-1331, out. 2013 DOI: $10.1590 / \mathrm{S} 0100-204 \mathrm{X} 2013001000003$ 
pastagem são explicados pelo maior número de anos em pastagem, em relação aos anos em lavoura de grãos. Neste sistema, do total de 20 anos de experimento, em 12 anos a área foi ocupada com pastagem, contra 7 anos na ILP com rotação iniciada com lavoura (Tabela 1). Além disso, os 13 anos de exploração de grãos, em rotação lavoura/pasto, ocasionaram alto investimento energético proveniente da adubação, em relação à rotação pasto/lavoura (Tabela 4).

Entre os sistemas ILP que se iniciaram com pastagem (S3P) em preparo convencional, a produção de carne foi acima daquela produzida com plantio direto, o que resultou em maior consumo energético associado aos insumos para a sanidade e consumo de sal mineral. A conversão do produto carne em energia gera saída energética mais positiva do que as entradas pelo investimento gasto na sua produção, e isto foi suficiente para compensar o maior investimento energético despendido no preparo do solo. Comportamento semelhante foi observado nos sistemas de ILP que se iniciaram com lavoura (S3L), em que, além da

Tabela 4. Balanço energético no sistema misto de produção com integração lavoura-pecuária, rotação pasto/lavoura S3P e rotação lavoura/pasto $\mathrm{S} 3 \mathrm{~L}$, com preparo convencional do solo (PC) e em sistema plantio direto (PD), entre 1991-2010, em experimento da Embrapa Cerrados, Planaltina, DF.

\begin{tabular}{lcccc}
\hline Sistema de manejo & S3PPC & S3PPD & S3LPC & S3LPD \\
\hline Ganho de peso animal $\left(\mathrm{Mg} \mathrm{ha}^{-1}\right)$ & 4,26 & 3,28 & 3,00 & 2,33 \\
Produtividade dos grãos $\left(\mathrm{Mg} \mathrm{ha}^{-1}\right)$ & 28,98 & 29,00 & 40,40 & 37,13 \\
Ingressos (GJ ha $\left.{ }^{-1}\right)$ & & & & \\
Fertilizantes/corretivos & 23,47 & 23,47 & 27,01 & 27,01 \\
Sementes & 9,85 & 9,85 & 20,11 & 20,11 \\
Inoculante & 0,03 & 0,03 & 0,06 & 0,06 \\
Inseticidas & 0,19 & 0,19 & 0,24 & 0,24 \\
Fungicidas & 0,91 & 0,91 & 1,28 & 1,28 \\
Herbicidas & 1,24 & 6,71 & 4,08 & 15,01 \\
Óleo mineral parafínico & 0,11 & 0,13 & 0,22 & 0,25 \\
Sanidade animal & 0,17 & 0,15 & 0,10 & 0,09 \\
Sal mineral & 0,17 & 0,15 & 0,10 & 0,09 \\
Combustível & 26,45 & 12,45 & 41,28 & 23,69 \\
Mão de obra & 19,13 & 19,13 & 19,13 & 19,13 \\
\hline Total de ingressos (a) & 81,72 & 73,17 & 113,61 & 106,96 \\
\hline Rendimento energético (GJ ha $\left.{ }^{-1}\right)$ & & & & \\
Energia do componente animal & 5370,14 & 4103,23 & 3782,55 & 2914,09 \\
Energia da combustão completa dos grãos & 651,00 & 554,38 & 923,18 & 657,47 \\
Energia total produzida pelo sistema (b) & 6021,14 & 4657,61 & 4705,73 & 3571,56 \\
Saldo energético médio (b-a)/20anos & 296,97 & 229,22 & 229,84 & 173,47 \\
\hline Balanço energético & 73,68 & 63,65 & 43,21 & 34,93 \\
\hline
\end{tabular}

Pesq. agropec. bras., Brasília, v.48, n.10, p.1323-1331, out. 2013

DOI: 10.1590/S0100-204X2013001000003 diferença apresentada na produção de carne, observouse deficit de 3,27 $\mathrm{Mg} \mathrm{ha}^{-1}$ na produtividade dos grãos no plantio direto (Tabela 4).

A eficiência energética de produtos agrícolas foi associada principalmente às entradas energéticas do uso de fertilizante, enquanto as eficiências energéticas de combustível e herbicida dependeram do manejo de solo utilizado. Do montante de investimento energético nos sistemas ILP, o consumo energético associado ao uso de herbicida foi de 9,17 e $14,67 \%$ em plantio direto, para S3P e S3L, respectivamente. No preparo convencional, o consumo associado ao combustível representou 32,36 e 37,9\%, no S3P e S3L, respectivamente (Tabela 4). Soares et al. (2007) observaram que o consumo atribuído ao combustível correspondeu a $16,54 \%$, e o uso de herbicidas somou $17,44 \%$, em plantio de soja e milho, em plantio direto, em ILP no experimento da Embrapa Arroz e Feijão, em Santo Antônio de Goiás, GO. O sistema de ILP apresentou melhores índices de conversão energética do que aos de produção contínua de grãos, o que pode ser explicado pela não utilização de fertilizantes na implantação da pastagem.

O balanço energético da soja, na produção de biodiesel, apresentou valores entre 1,3:1 e 2,0:1 que, embora baixos, foram positivos, com tendência de melhor eficiência energética do biodiesel quando os grãos foram produzidos em plantio direto (Tabela 5). O sistema ILP iniciado com lavoura apresentou os menores valores de eficiência $(1,3$ em plantio convencional e 1,4 em plantio direto), seguido pelo sistema de lavoura contínua. A melhor conversão energética foi observada naquele iniciado com pastagem, pela maior produtividade de grãos de soja (Tabela 5).

Para que o biocombustível derivado de uma fonte possa ser considerado em um programa bioenergético, o balanço energético deve ser superior a 1 (um). No presente trabalho, o balanço energético do milho, na produção de bioetanol, apresentou valores entre 2,3:1 e $3,2: 1$, em que todos os sistemas apresentaram valores acima daqueles observados no biodiesel (Tabela 6). Na produção do bioetanol, o sistema de produção de grãos contínuo em plantio direto apresentou maior eficiência energética em comparação ao plantio convencional, enquanto o oposto foi observado nos sistemas integrados (S3L e S3P), pela menor produtividade do milho em plantio direto. Santos et al. (2011) avaliaram a conversão e o balanço de energia de 
uma série de sistemas de produção, em plantio direto, e observaram que o milho foi a cultura mais eficiente quanto ao retorno energético, na comparação com outros grãos. Soares et al. (2007) encontraram valores de conversão energética para o biodiesel e bioetanol de 1,42:1 e 1,51:1, respectivamente, em um experimento de ILP no Cerrado. Outro estudo de balanço energético do bioetanol do milho, realizado na região do Médio Paranapanema, SP, resultou em valor correspondente a 1,2:1 (Salla et al., 2010).

Em geral, os resultados de balanço energético obtidos no presente estudo foram favoráveis aos biocombustíveis produzidos em todos os sistemas, especialmente o bioetanol. O balanço energético de biocombustíveis a partir do milho pode melhorar por meio da exploração de variedades mais produtivas ou menos dependentes de insumos agrícolas, redução e substituição da adubação nitrogenada pelo uso de adubo verde, em consórcio ou em sucessão, de forma a reduzir o custo energético e econômico da produção (Urquiaga et al., 2005). Os resultados evidenciam que o sistema ILP não compromete a exploração de culturas energéticas; além disto, proporciona ao produtor diversidade de renda e permite driblar a sazonalidade dos preços pagos ao produto no mercado.

Tabela 5. Balanço energético do biodiesel de soja, em sistemas especializados e mistos de produção de grãos, em plantio direto e preparo convencional do solo, durante o período de 1991-2010, em experimento da Embrapa Cerrados, Planaltina, DF.

\begin{tabular}{|c|c|c|c|c|c|c|}
\hline \multirow[t]{2}{*}{ Sistemas de preparo do solo } & \multicolumn{2}{|c|}{ Lavoura contínua } & \multicolumn{2}{|c|}{$\begin{array}{l}\text { Integração lavoura-pecuária } \\
\text { rotação lavoura/pasto }\end{array}$} & \multicolumn{2}{|c|}{$\begin{array}{c}\text { Integração lavoura-pecuária } \\
\text { rotação pasto/lavoura }\end{array}$} \\
\hline & Convencional & Plantio Direto & Convencional & Plantio Direto & Convencional & Plantio Direto \\
\hline \multicolumn{7}{|l|}{ Produtividade $\left(\mathrm{Mg} \mathrm{ha}^{-1}\right)$} \\
\hline Grãos de soja & 2,26 & 2,37 & 2,10 & 2,11 & 3,19 & 3,23 \\
\hline Óleo de soja & 0,41 & 0,43 & 0,38 & 0,38 & 0,58 & 0,58 \\
\hline \multicolumn{7}{|l|}{ Ingressos $\left(\mathrm{GJ}\right.$ ha $\left.^{-1}\right)$} \\
\hline Transesterificação industrial & 3,5 & 3,7 & 3,3 & 3,3 & 5,0 & 5,0 \\
\hline Produção agrícola & 7,7 & 6,3 & 7,8 & 7,4 & 7,0 & 6,4 \\
\hline Consumo energético total & 11,2 & 10,0 & 11,1 & 10,7 & 12,0 & 11,4 \\
\hline \multicolumn{7}{|l|}{ Produção(GJ ha'-1) } \\
\hline Energia produzida pelo biodiesel & 15,9 & 16,7 & 14,7 & 14,8 & 22,4 & 22,7 \\
\hline Balanço energético & 1,4 & 1,7 & 1,3 & 1,4 & 1,9 & 2,0 \\
\hline
\end{tabular}

Tabela 6. Balanço energético do bioetanol de milho, em sistemas especializados e mistos de produção de grãos, em sistema plantio direto (PD) e preparo convencional do solo (PC), durante 1991-2010, em experimento da Embrapa Cerrados, Planaltina, DF.

\begin{tabular}{|c|c|c|c|c|c|c|}
\hline \multirow[t]{2}{*}{ Sistemas de preparo do solo } & \multicolumn{2}{|c|}{ Lavoura contínua } & \multicolumn{2}{|c|}{$\begin{array}{c}\text { Integração lavoura-pecuária rotação } \\
\text { lavoura/pasto }\end{array}$} & \multicolumn{2}{|c|}{$\begin{array}{c}\text { Integração lavoura-pecuária rotação } \\
\text { pasto/lavoura }\end{array}$} \\
\hline & Convencional & Plantio Direto & Convencional & Plantio Direto & Convencional & Plantio Direto \\
\hline \multicolumn{7}{|l|}{ Produtividade $\left(\mathrm{Mg} \mathrm{ha}^{-1}\right)$} \\
\hline Grãos de milho & 6,91 & 6,64 & 8,65 & 7,81 & 4,26 & 4,10 \\
\hline Bioetanol & 2,07 & 1,99 & 2,59 & 2,34 & 1,28 & 1,23 \\
\hline \multicolumn{7}{|l|}{ Ingressos $\left(\mathrm{GJ}^{\mathrm{h}} \mathrm{h}^{-1}\right)$} \\
\hline $\begin{array}{l}\text { Hidrólise e sacarificação do amido } \\
\text { e fermentação industrial }\end{array}$ & 7,3 & 7,0 & 9,2 & 8,3 & 4,5 & 4,3 \\
\hline Produção agrícola & 11,6 & 9,4 & 14,3 & 14,2 & 9,8 & 9,7 \\
\hline Consumo energético total & 18,9 & 16,4 & 23,5 & 22,5 & 14,3 & 14,0 \\
\hline \multicolumn{7}{|l|}{ Produção (GJ ha'-1) } \\
\hline Energia produzida pelo bioetanol & 55,0 & 52,9 & 68,9 & 62,2 & 33,9 & 32,6 \\
\hline Balanço energético & 2,9 & 3,2 & 2,9 & 2,7 & 2,4 & 2,3 \\
\hline
\end{tabular}




\section{Conclusões}

1. Os produtos agrícolas produzidos nos sistemas mistos apresentam balanço energético e produção absoluta de energia renovável compatíveis com aqueles produzidos em sistemas especializados.

2. Os sistemas especializados de produção de grãos, independentemente do sistema de preparo do solo, apresentam o menor balanço energético e a menor produção absoluta de energia renovável por unidade de área.

3. O balanço energético do biodiesel de soja apresenta valores favoráveis tanto em sistemas mistos como especializados, independentemente do sistema de preparo de solo.

4. O bioetanol produzido com milho apresenta maior balanço energético.

\section{Agradecimentos}

À Embrapa Agrobiologia e à Embrapa Cerrados, pelo apoio técnico e financeiro ao projeto; e ao Conselho Nacional de Desenvolvimento Científico e Tecnológico (CNPq), por concessão de bolsa.

\section{Referências}

ASSENHEIMER, A.; CAMPOS, A.T.; GONÇALVES JÚNIOR, A.C. Análise energética de sistemas produção de soja convencional e orgânica. Ambiência, v.5, p.443-455, 2009.

BODDEY, R.M.; SOARES, L.H. de B.; ALVES, B.J.R.; URQUIAGA, S. Bio-ethanol production in Brazil. In: PIMENTEL, D. (Ed.). Biofuels, solar and wind as renewable energy systems. Dordrecht: Springer, 2008. p.321-356. DOI: 10.1007/978-1-40208654-0_13.

CAMPOS, A.T.; CAMPOS, A.T. de. Balanços energéticos agropecuários: uma importante ferramenta como indicativo dos agrossistemas. Ciência Rural, v.34, p.1977-1985, 2004. DOI: 10.1590/S0103-84782004000600050.

CAMPOS, A.T.; KLOSOWSK, E.S.; SOUZA, C.V.; ZANINI, A.; PRESTES, T.M.V. Análise energética da produção de soja em sistema de plantio direto. Global Science and Technology, v.2, p.38-44, 2009.

CAMPOS, A.T.; SAGLIETTI, J.R.C.; BUENO, O. de C.; CAMPOS, A.T. de; KLOSOWSKI, E.S.; GASPARINO, E. Balanço energético na produção de feno de alfafa em sistema intensivo de produção de leite. Ciência Rural, v.34, p.245-251, 2004. DOI: 10.1590/S0103-84782004000100038.

CHERUBINI, F.; STRØMMAN, A.H. Life cycle assessment of bioenergy systems: state of the art and future challenges. Bioresource Technology, v.102, p.437-451, 2011. DOI: 10.1016/j. biortech.2010.08.010.
CUCEK, L.; KLEMES, J.J.; Kravanja, Z. Carbon and nitrogen trade-offs in biomass energy production. Clean Technologies and Environmental Policy, v.14, p.389-397, 2012. DOI: 10.1007/ s10098-012-0468-3.

MACEDO, I.C.; SEABRA, J.E.A.; SILVA, J.E.A.R. Green house gases emissions in the production and use of ethanol from sugarcane in Brazil: the 2005/2006 averages and a prediction for 2020. Biomass and Bioenergy, v.32, p.582-595, 2008. DOI: 10.1016/j.biombioe.2007.12.006.

MARTA JÚNIOR, G.B. Dinâmica de uso da terra em resposta à expansão da cana-de-açúcar no Cerrado. Revista de Política Agrícola, ano 17, p.31-43, 2008.

MELLO, R. de. Um modelo para análise energética de agroecossistemas. Revista de Administração de Empresas, v.29, p.45-61, 1989. DOI: 10.1590/S0034-75901989000400005.

MELO, D. de; PEREIRA, J.O.; SOUZA, E.G. de; GABRIEL FILHO, A.; NÓBREGA, L.H.P.; PINHEIRO NETO, R. Balanço energético do sistema de produção de soja e milho em uma propriedade agrícola do oeste do Paraná. Acta Scientiarum. Agronomy, v.29, p.173-178, 2007. DOI: 10.4025/actasciagron. v29i2.233.

PIMENTEL, D. (Ed.). Handbook of energy utilization in agriculture. Boca Raton: CRC Press, 1980. 475p.

PIMENTEL, D.; HALL, C.W. (Ed.). Food and energy resources. Orlando: Academic Press, 1984. 268p. (Food science and technology. A series of monographs).

PLANO Nacional de Agroenergia 2006-2011. 2.ed. rev. Brasília: Embrapa Informação Tecnológica, 2006. 118p.

RONDÓN, P.P.; NOGUERA, P.L.; MORALES, A.A. Costo energético de tres sistemas de labranza en el cultivo de maíz. Revista Ciencias Técnicas Agropecuarias, v.14, p.23-27, 2005.

ROSTAGNO, H.S.; ALBINO, L.F.T.; DONZELE, J.L.; GOMES, P.C.; OLIVEIRA, R.F.; LOPES, D.C.; FERREIRA, A.S.; BARRETO, S.L.T. Tabelas brasileiras para aves e suínos: composição de alimentos e exigências nutricionais. 2.ed. Viçosa: Ed. da UFV, 2005.

SALlA, D.A.; FURLANETO, F. de P.B.; CABELlO, C.; KANTHACK, R.A.D. Estudo energético da produção de biocombustível a partir do milho. Ciência Rural, v.40, p.2017-2022, 2010. DOI: 10.1590/S0103-84782010005000142.

SANT'ANA, N. de F.; FONTES, C.A. de A.; SILVA, R.S.T. da; GARCIA, C. de S.; VIEIRA, R.A.M.; ROCHA, T.C. Body composition and net requirements of protein and energy for weight gain of Nellore and crossbreed steers finished under grazing. Revista Brasileira de Zootecnia, v.40, p.912-921, 2011. DOI: 10.1590/S1516-35982011000400028.

SANTOS, H.P. dos; FONTANELI, R.S.; SPERA, S.T.; MALDANER, G.L. Energy conversion and balance of integrated crop-livestock production systems under no-tillage. Pesquisa Agropecuária Brasileira, v.46, p.1193-1199, 2011. DOI: 10.1590/ S0100-204X2011001000011.

SANTOS, H.P. dos; TOMM, G.O.; SPERA, S.T.; ÁVILA, A. Efeito de práticas culturais na conversão e no balanço 
energéticos. Bragantia, v.66, p.299-306, 2007. DOI: 10.1590/ S0006-87052007000200014.

SOARES, L.H. de B.; MUNIZ, L.C.; FIGUEIREDO, R.S.; ALVES, B.J.R.; BODDEY, R.M.; URQUIAGA, S.; MADARI, B.E.; MACHADO, P.L.O. de A. Balanço energético de um sistema integrado lavoura-pecuária no Cerrado. Seropédica: Embrapa Agrobiologia, 2007. 32p. (Embrapa Agrobiologia. Boletim de pesquisa e desenvolvimento, 26).
URQUIAGA, S.; ALVES, B.J.R.; BODDEY, R.M. Produção de biocombustíveis: a questão do balanço energético. Revista de Política Agrícola, ano 14, p.42-46, 2005.

VILELA, L.; MARTHA JUNIOR, G.B.; MACEDO, M.C.M.; MARCHÃO, R.L.; GUIMARAES JUNIOR, R.; PULROLNIK, K.; MACIEL, G.A. Sistemas de integração lavoura-pecuária na região do cerrado. Pesquisa Agropecuária Brasileira, v.46, p.1127-1138, 2011. DOI: 10.1590/S0100-204X2011001000003.

$\overline{\text { Recebido em } 19 \text { de março de } 2013 \text { e aprovado em } 30 \text { de setembro de } 2013}$ 